\title{
Controle Remoto: observando códigos com o Arduíno (parte 2 de 2) ${ }^{+*}$
}

Marisa Almeida Cavalcante

Departamento de Física - PUC

São Paulo - SP

Thais Tokashiki Tavares Rodrigues

Aluna do curso de licenciatura em Física - PUC/SP

Darlene Andrea Bueno

Aluna do curso de bacharelado em Física - PUC/SP

São Paulo - SP

\section{Resumo}

Este trabalho tem como principal objetivo a difusão da utilização do microcontrolador Arduíno, no ensino e aprendizagem de Física Moderna. Para isso elaboramos uma sequência didática com o objetivo de explorar o funcionamento de controles remoto. Experimentos são propostos de forma a tornar possivel, a compreensão não apenas do seu funcionamento, mas como se processa os diferentes comandos advindos de cada uma de suas teclas. Pretendemos com isso explorar conceitos de física a partir de instrumentos e aplicações tecnológicas presentes no dia a dia dos estudantes, tornando as aulas de Física mais dinâmicas e motivadoras.

Palavras-chave: Controle Remoto. Arduíno. Física Moderna.

\footnotetext{
${ }^{+}$Operation of a Remote Control: Observing the codes with Arduino (Part 2 of 2)

* Recebido: maio de 2014. Aceito: junho de 2014.
} 


\begin{abstract}
The objective of this work is to popularize the use of the Arduino micro-controller, in teaching and learning of Modern Physics. To facilitate this action we develop a didactic sequence to explore the operation of remote controls. We propose a few experiments to make possible an understanding not only of its operation, but as it processes the commands different from each of its keys. We intend to explore these concepts of Physics tools and technology applications in everyday life of students, making Physics classes more dynamic and motivating.
\end{abstract}

Keywords: Remote Control. Arduino. Modern Physics.

\title{
I. Introdução
}

Nos últimos anos acompanhamos avanços científicos e tecnológicos extraordinários que acarretaram em grandes transformações econômicas, políticas, sociais e culturais. A escola deve assegurar a todos indivíduos uma formação cientifica e cultural adequada tanto para sua vida pessoal, quanto profissional possibilitando uma relação crítica e participativa em todas as instancias desta nova sociedade.

A sociedade do século XXI exige cada vez mais a cidadãos com maior competência reflexiva e critica diante das diferentes mídias existentes, grande flexibilidade de transitar em diferentes universos culturais, com amplo domínio das tecnologias disponíveis e autonomia para absorver o novo. Aliado à estas competências é preciso capacidade de diálogo e comunicação com os demais, consciência e responsabilidade social e ambiental. A escola deste século deve, portanto, ser um espaço de integração que garanta a formação deste cidadão, com uma formação sólida, disposto sempre a aprender, capaz de atuar de modo crítico diante das grandes transformações tecnológicas e cientificas que vivemos.

... As tarefas de construção de uma democracia econômica e política pertencem a várias esferas de atuação da sociedade e a escola é apenas uma delas. Mas a escola tem um papel insubstituível quando se trata de preparação das novas gerações para enfrentamento das exigências postas pela sociedade moderna ou pós-moderna... A escola tem, pois, o compromisso de reduzir a distância entre a ciência cada vez mais complexa e a cultura de 
base produzida no cotidiano e provida pela escolarização (LIBÂNEO, 2013, p.11).

Em outras palavras a escola mais do que nunca, tem a tarefa de promover a alfabetização científica para todos.

... Em definitivo, a participação dos cidadãos na tomada de decisões é hoje um fato positivo, uma garantia de aplicação do principio de precaução, que se apoia numa crescente sensibilidade social face as implicações do desenvolvimento tecnológico que pode comportar riscos para as pessoas ou para o meio ambiente. Tal participação, temos que insistir, reclamam um mínimo de formação científica que torne possível a compreensão dos problemas e das opções (CACHAPUZ et al., 2005).

Este trabalho surge, portanto, dentro desta perspectiva: "propiciar alfabetização científica com temas mais atuais para sala de aula”, procurando trazer uma linguagem acessível para a compreensão de todo o mecanismo de transmissão e recepção de sinais sem fio em sistemas com controle remoto.

Além de este tema estar muito presente no cotidiano dos estudantes permite abordar não apenas os conceitos associados à Física Moderna, como por exemplo, o efeito fotoelétrico, mas também a transmissão ótica de sinais, e que apresenta um alto grau de complexidade técnica e científica. Podemos dizer que o cenário principal é o efeito fotoelétrico, no entanto farão parte deste quadro a compreensão do "modo como se propaga a informação" e da "frase binária" que incide sobre o receptor bem como os comandos que podem ser associados a cada uma destas frases.

Para propiciar esta compreensão o trabalho foi apresentado em duas partes. Na parte 1 (CAVALCANTE et. al., 2013), apresentamos uma sequência de atividades para explorar os aspectos conceituais e físicos envolvidos no processo de recepção de sinais infravermelho. Nesta a segunda etapa (mais técnica), daremos maior ênfase às frases binárias associadas a cada comando advindo do controle remoto e utilizaremos o Arduíno para interpretar os códigos recebidos e exercer uma ação específica, tal como ocorre em receptores domésticos, como aparelhos de TV, DVD, ar condicionado, dentre outros. 


\section{Controle remoto}

\section{II.1 Frase binária}

Vimos na parte 1 deste trabalho, que o controle remoto IR envia pulsos da radiação infravermelha que representam códigos binários específicos. Para cada código é associado um dado comando como, por exemplo, aumentar o volume ou trocar de canal. O receptor infravermelho (IR) disposto num dado aparelho recebe os pulsos de luz em dados binários. A Fig. 1 mostra um exemplo de sinal observado, ao apertar uma determinada tecla de um controle, onde o eixo vertical está associado a uma variável proporcional a amplitude do sinal e o eixo horizontal ao tempo (neste caso em segundos).

Cada sinal proveniente de controle remoto deve ser composto, no mínimo, por quatro subcódigos:

- Iniciar, que indica ou "avisa" o receptor que um determinado comando será enviado;

- Uma sequência que indica o comando específico (por exemplo, aumentar o volume);

- O endereçamento que indica o fabricante e/ou aparelho;

- Parar (sinal disparado quando se libera uma determinada tecla, por exemplo, "aumentar o volume").

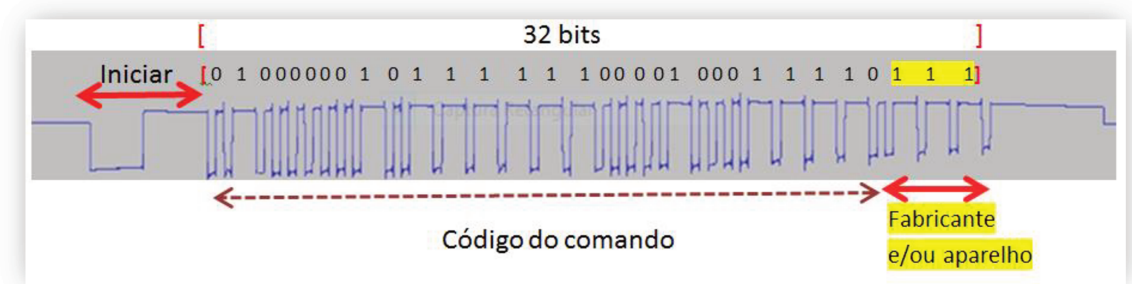

Fig. 1 - Subcódigos contidos na frase binária enviada por um controle remoto "tecla 4" observado através do software de som de versão freeware Audacity. 
Após o subcódigo "iniciar", temos 32 bits (estado 1 ou 0 ) onde; um pulso de maior duração está associado ao "bit 1 " e o de menor ao "bit 0 ".

Este sinal é recebido e processado de tal modo que cada tecla está associada a um código, que por sua vez, terá um comando específico. Em outras palavras é necessário existir uma espécie de "tradutor" que deve receber estes pulsos armazená-los em uma frase de 32 bits, que contempla um dado comando.

\section{II.2 Sistemas de numeração: decimal, binária e hexadecimal}

Para melhor compreender as informações contidas nos pulsos de radiação infravermelha enviada pelo controle remoto é necessário compreender como representamos um determinado número nas bases decimal, binária e hexadecimal.

\section{II.3 Sistema de numeração binária e decimal}

O sistema binário utiliza apenas dois valores de tensão para representar dois estados; estado alto (ou sistema conduz) que corresponde a aproximadamente de 5 Volts (bit 1) e o estado baixo (sistema não conduz), aproximadamente 0 Volts (bit 0), ou seja é um sistema de base dois. Nos computadores, zeros e uns são chamados de dígitos binários ou somente bit, que é a menor unidade de informação dos computadores.

Uma frase binária pode ser representada com um conjunto de bits e pode estar associada a um dado numero da base decimal.

Escrever um número inteiro em binário, isto é, na base dois, é relativamente simples. Cada posição digital representará uma potência de dois, da mesma forma que nos números decimais, cada posição representa uma potência de dez.

Assim o número 53, na base dez (base decimal) é dado por:

$$
0 \times 10^{5}+0 \times 10^{4}+0 \times 10^{3}+0 \times 10^{2}+5 \times 10^{1}+3 \times 10^{0}=0+0+0+0+50+3=53
$$

Na base dois, o número 53 é dado por 110101 cuja transformação de base pode ser vista a seguir:

$$
1 \times 2^{5}+1 \times 2^{4}+0 \times 2^{3}+1 \times 2^{2}+0 \times 2^{1}+1 \times 2^{0}=32+16+0+4+0+0+1=53
$$

\footnotetext{
${ }^{1}$ Bit é a menor unidade de informação que pode ser armazenada ou transmitida em processadores. Para o bit 1 temos um processo de condução de eletricidade e a tensão observada, em geral, em torno de $5 \mathrm{~V}$, com estado lógico verdadeiro. Para o bit 0 não há condução e a tensão está torno de $0 \mathrm{~V}$ ou alguns $\mathrm{mV}$, com estado lógico falso.
} 
Para frase constituída de 3 bits teremos $2^{3}$ frases binárias possíveis. Para frases constituídas por 8 bits permitem $2^{8}$ possibilidades diferentes, que corresponde a 256 frases. Para 16 bits teremos $2^{16}$ frases possíveis, ou seja, 65536 frases. Para $\mathrm{n}$ bits, teremos $2^{\mathrm{n}}$ frases possíveis.

Se para cada frase associarmos um dado comando, teremos $2^{\mathrm{n}}$ comandos distintos para frases constituídas por $\mathrm{n}$ bits.

Quando apertamos um dado botão do controle remoto, uma sequência de bits que constitui uma frase binária é produzida e que pode ser percebida, por exemplo, com o piscar do led em uma câmera digital ou ainda através do audacity, como vimos na parte 1 deste artigo.

\section{II.4 Sistema de numeração hexadecimal}

O sistema hexadecimal é um sistema de numeração posicional que representa os números em base 16, portanto, empregando 16 símbolos. Ou seja, além dos dez números, ele deve incluir seis letras adicionais, para completar o sistema. O conjunto de símbolos fica, portanto, assim:

$$
\mathrm{S}=[0,1,2,3,4,5,6,7,8,9, \mathrm{~A}, \mathrm{~B}, \mathrm{C}, \mathrm{D}, \mathrm{E}, \mathrm{F}]
$$

Para a conversão de um número binário para hexadecimal é importante saber que um dígito em hexadecimal pode representar um número binário de 4 dígitos, dessa forma, para transformar um binário em hexadecimal devemos separar o binário em grupos de 4 bits, começando sempre pela direita.

Suponha por exemplo o número 110101 que corresponde como vimos o numero 53 na base decimal:

Devemos separar esta frase em dois conjuntos de quatro dígitos começando pela direita o que nos fornece:
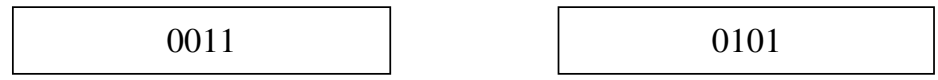

Para os quatro dígitos, 0011 temos o numero 3, já para os quatro dígitos 0101 temos o numero 5. Assim o hexadecimal correspondente é 35 .

A tabela abaixo fornece a representação nas bases; decimal, binária e hexadecimal dos números 0 a 15 (16 símbolos desta base). 
Tabela 1 - Tabela de conversão decimal-binário- hexadecimal.

\begin{tabular}{|c|c|c|}
\hline Decimal & Binário & Hexadecimal \\
\hline 0 & 0000 & 0 \\
\hline 1 & 0001 & 2 \\
\hline 2 & 0010 & 3 \\
\hline 3 & 0011 & 4 \\
\hline 4 & 0100 & 5 \\
\hline 5 & 0101 & 6 \\
\hline 6 & 0110 & 7 \\
\hline 7 & 0111 & 8 \\
\hline 8 & 1000 & 9 \\
\hline 9 & 1001 & $0 \mathrm{~A}$ \\
\hline 10 & 1010 & $0 \mathrm{~B}$ \\
\hline 11 & 1011 & $0 \mathrm{C}$ \\
\hline 12 & 1100 & $0 \mathrm{D}$ \\
\hline 13 & 1101 & $0 \mathrm{E}$ \\
\hline 14 & 1110 & $0 \mathrm{~F}$ \\
\hline 15 & 1111 & \\
\hline & & \\
\hline
\end{tabular}

\section{II.5 Representando a frase de 32 bits do controle remoto em hexadecimal}

Como vimos no item 2.2 para obter a decodificação em hexadecimal de uma frase binária devemos dividir o sinal associado ao comando em conjuntos de quatro bits, como indica o quadro 1, referente ao sinal observado na Fig. 1 (item 2.1)

Quadro 1 - Decodificação frase binária em hexadecimal: "Tecla 4 - 40BF08F7"

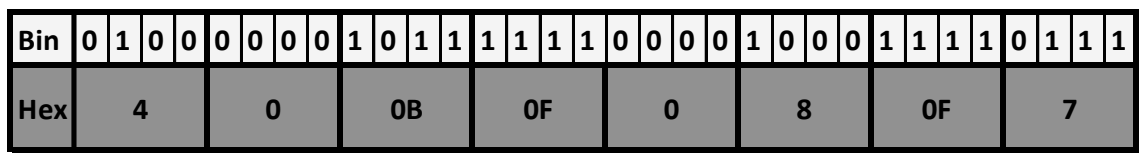


As Fig. 2 e 3 fornecem uma sequência de imagens obtidas para as teclas EQ e tecla 6, respectivamente, do mesmo controle remoto. Nos quadros 2 e 3 disponibilizamos a representação do código em hexadecimal para as teclas correspondentes.

\section{Tecla EQ}

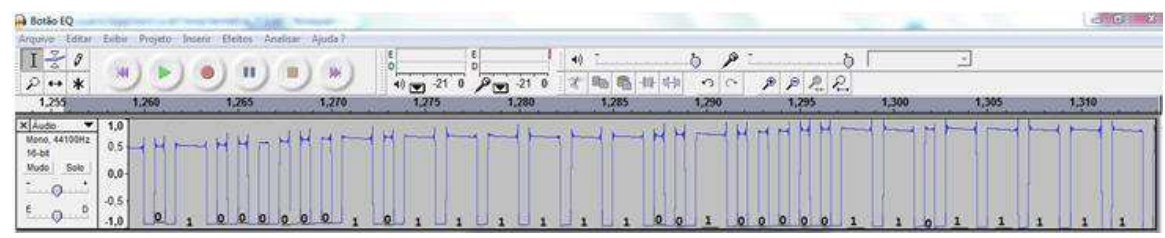

Fig. 2 - Tecla EQ do controle remoto hexadecimal correspondente.

Quadro 2 - Frase binária para hexadecimal: Tecla EQ- 40BF20DF.

\begin{tabular}{|c|c|c|c|c|c|c|c|c|}
\hline Bin & \begin{tabular}{|l|l|l|l|}
0 & 1 & 0 & 0 \\
\end{tabular} & \begin{tabular}{|l|l|l|l|}
0 & 0 & 0 & 0 \\
\end{tabular} & \begin{tabular}{l|l|l|l|}
1 & 0 & 1 & 1 \\
\end{tabular} & \begin{tabular}{|l|l|l|l|}
1 & 1 & 1 & 1 \\
\end{tabular} & \begin{tabular}{|l|l|l|l|}
0 & 0 & 1 & 0 \\
\end{tabular} & 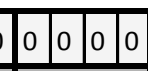 & \begin{tabular}{|l|l|l|l|}
1 & 1 & 0 & 1 \\
\end{tabular} & 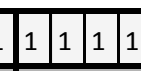 \\
\hline $\operatorname{Hex}$ & 4 & 0 & $O B$ & $\mathrm{OF}$ & 2 & 0 & OD & $\mathrm{OF}$ \\
\hline
\end{tabular}

\section{Tecla 6}

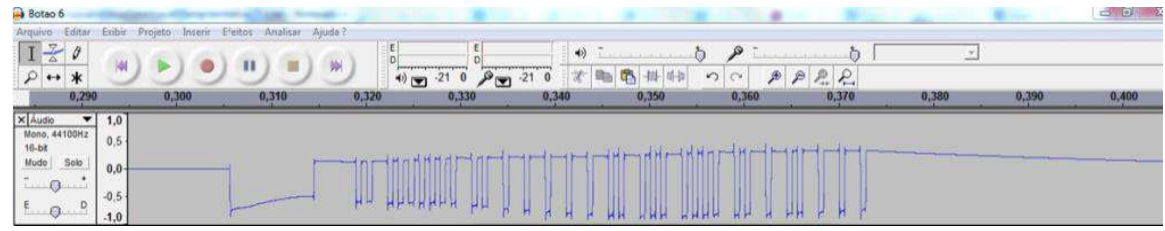

Fig. 3 - Tecla 6 do controle remoto.

Quadro (3) - Frase binária na base hexadecimal para a Tecla 6: 40BF48B7.

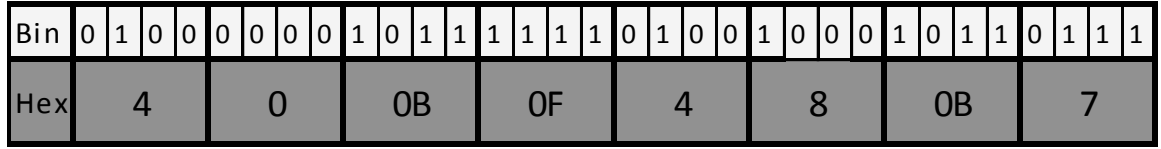


Dando continuidade à sequência didática, observaremos com o microcontrolador Arduíno o código hexadecimal de cada frase binária, utilizando o receptor IR da serie PNA4601M e uma biblioteca específica para este fim. Para cada hexadecimal, teremos um comando associado através de programação na IDE (Integrated Development Environment) do Arduíno. Esta leitura permitirá comparar o hexadecimal obtido a partir do software Audacity com o indicado na saída serial da IDE do Arduíno.

\section{Arduíno}

O Arduíno (Fig. 4) é uma plataforma física de computação de código aberto, baseada em uma placa microcrontroladora que possui protótipos eletrônicos flexíveis com base em hardware e software fáceis de usar e open-source.

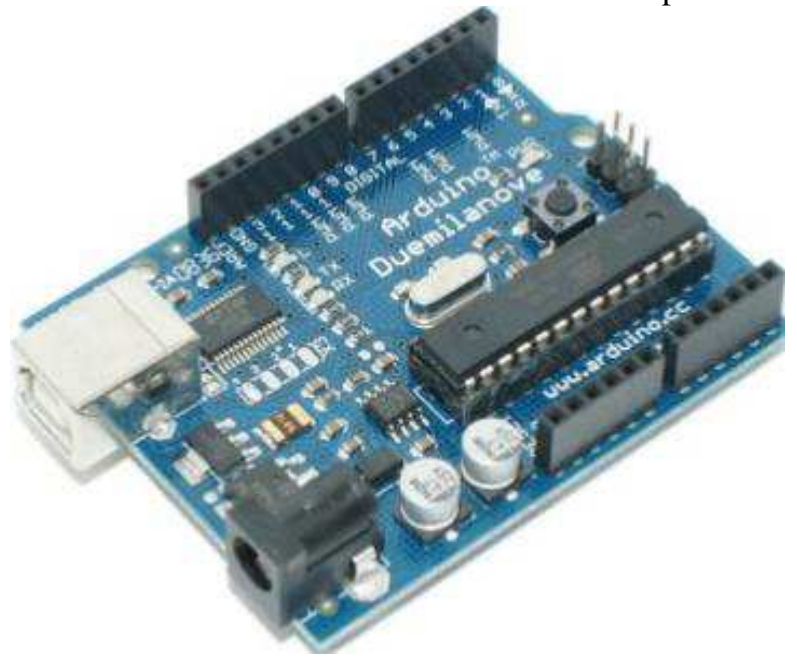

Fig. 4 - Placa Arduíno Duemilanove.

O Arduíno atua não apenas como uma placa de aquisição e conversão de sinais, mas pode exercer ações a partir de informações capturadas por sensores acoplados as suas entradas. A linguagem de programação do Arduíno é uma implementação do Wiring, que é um conjunto de funções $\mathrm{C} / \mathrm{C}++$, e tem seu desenvolvimento em um ambiente (IDE) do Arduíno, que é baseado no Processing. Projetos do Arduíno podem ser autônomos ou pode comunicar-se com o programa, rodando em um computador, pela saída USB. 
As placas podem ser constituídas manualmente ou compradas prémontados, o software pode ser baixado gratuitamente. Os projetos da montagem física de referência estão disponíveis sob uma licença de código aberto, de modo a se poder adaptá-la livremente a necessidade ou a vontade do usuário, o que conduz a experimentação de alta qualidade com um custo bastante reduzido.

Apesar da grande potencialidade do Arduíno no desenvolvimento de projetos na área educacional, ainda são poucos os trabalhos publicados para facilitar o ensino e a aprendizagem de Física, concomitantes ao aprendizado em programação nas áreas da Ciência da Computação e Engenharias. Alguns autores brasileiros como (SOUZA et al., 2011; CAVALCANTE et al., 2011; CAVALCANTE et al., 2013; MOLISANI et al., 2013; ALMEIDA JUNIOR et al., 2013; ALMEIDA JUNIOR et al., 2012; CAVALCANTE et al., 2012, DROSE, 2013) comentam em seus trabalhos o grande leque de possibilidades e vantagens de se utilizar a plataforma o Arduíno como uma importante ferramenta para o desenvolvimento de projetos correlacionados ao ensino e aprendizagem de Física, não apenas devido ao seu baixo custo, mas também por sua imensa rede cooperativa de usuários em diferentes idiomas em razão do seu sistema open-source em hardware e software.

\section{Kit controle remoto}

Neste experimento, o Arduíno atuará como um microprocessador, este receberá sinais digitais advindos do controle remoto IR, em uma das portas digitais. A recepção dos pulsos será realizada por receptores da série PNA4601M que compõe o kit Controle remoto encontrado no mercado (Fig. 5). Estes receptores são constituídos por circuitos integrados bipolares que interpretam e enviam estes sinais a uma das portas digitais do Arduíno. Utilizando uma biblioteca especificamente criada para estes receptores, o Arduíno fornece em sua saída serial a frase recebida em Hexadecimal em binário ou decimal. Para cada código recebido associamos na programação uma ação, como por exemplo, ligar um LED, alterar a cor de um LED RGB, ou ainda alterar a sua intensidade.

Convém esclarecer que podemos utilizar qualquer controle remoto (de qualquer fabricante), inclusive àqueles que se encontra em desuso, sendo este experimento uma boa oportunidade para a reciclagem de lixo eletrônico.

\section{IV.1 Receptor Infra -vermelho da série PNA4601M}

Receptores infravermelhos são pequenos chips com células fotoelétricas, ajustadas para a região Infravermelha do espectro eletromagnético, são utilizados 
em TVs e DVDs para detectar o pulso enviado pelo controle remoto. A célula fotoelétrica é um exemplo de componente que opera por meio de emissão fotoelétrica (emissão de fotoelétrons), este dispositivo geram uma pequena tensão elétrica quando são iluminados.

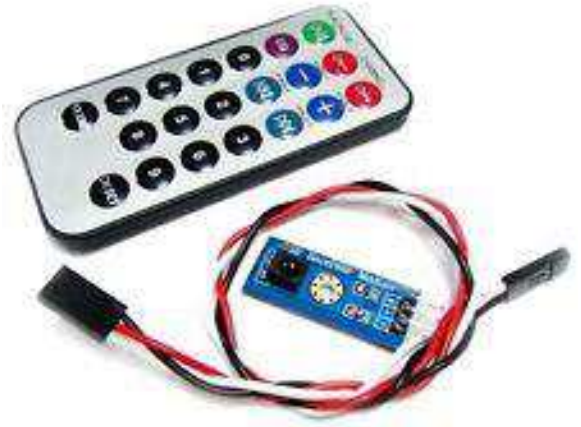

Fig. 5 - Kit controle remoto com receptor.

Os receptores IR são especialmente filtrados para a radiação infravermelha, diferentemente das células fotoelétricas "convencionais" que são boas para detectar radiação visível ou ultravioleta próxima e não são boas para detectar radiação infravermelha. Estes receptores são concebidos de maneira que os impulsos decorrentes de sinais de ruído ou perturbação são evitados. Um filtro passa-banda, um estágio integrador e um controle de ganho automático são usados para suprimir tais perturbações conforme indica o diagrama de blocos da Fig. 6.

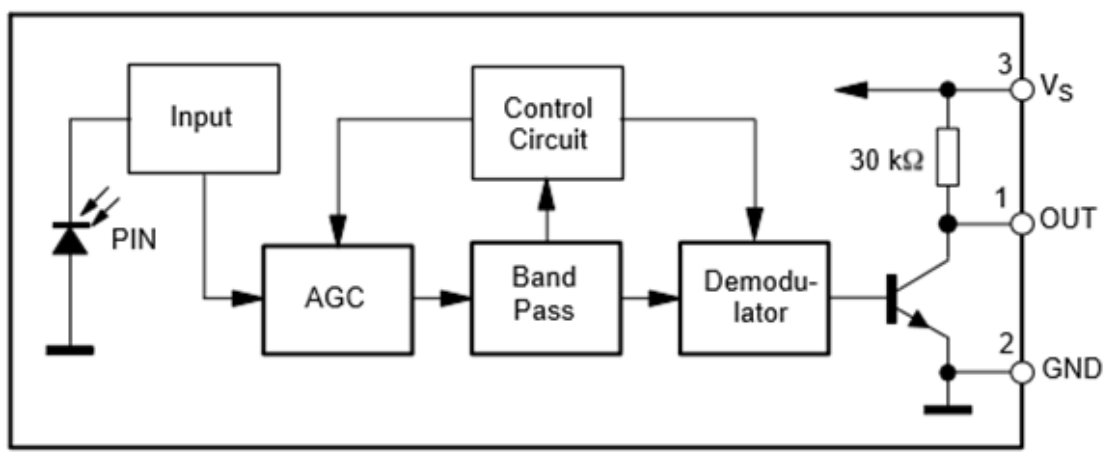

Fig. 6 - Diagrama de Blocos dos receptores IR. 
A maioria dos sinais, da forma como são fornecidos pelo transmissor, não podem ser enviados diretamente. Consequentemente é necessário modificar esse sinal através de uma onda eletromagnética portadora, cujas propriedades são mais convenientes aos meios de transmissão. A modulação é a alteração sistemática por uma onda portadora de acordo com a mensagem (sinal modulante), e pode incluir também uma codificação.

Para controles remotos a modulação dos sinais se dá por meio de modulação de largura de pulsos ou PWM (Pulse Width Modulation). Para este tipo de modulação se mantém a amplitude dos pulsos constantes e varia-se a sua largura proporcionalmente aos valores de (sinal modulador ou da onda portadora) nos instantes correspondentes, como mostra um exemplo da Fig. 7.

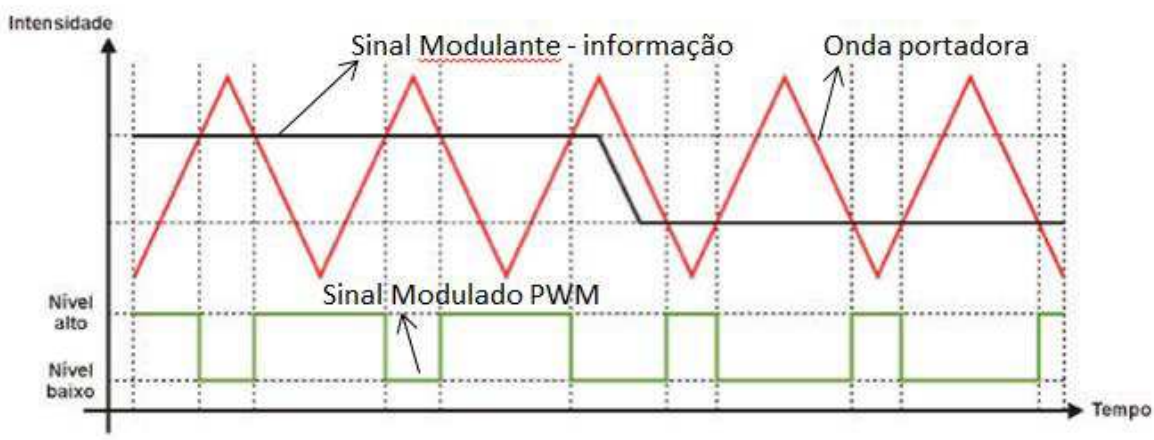

Fig. 7 - Exemplo de Modulação por largura de Pulso.

Como o sinal transmitido pelo controle remoto é um sinal modulado (PWM) os receptores IR possuem um demulador de largura de Pulso (PWM), para frequências de 33 a $43 \mathrm{kHz}$, de modo a obter a informação contida no sinal enviado. Já as células fotoelétricas não possuem demulador e podem detectar qualquer frequência que possua a resposta da fotocélula (próxima a $1 \mathrm{kHz}$ ).

O comprimento de onda no qual o receptor IR é sensível é de $940 \mathrm{~nm}$. As Fig. 8a e 8 b mostram a curva de resposta de frequência e sensibilidade espectral para o receptor utilizado. 


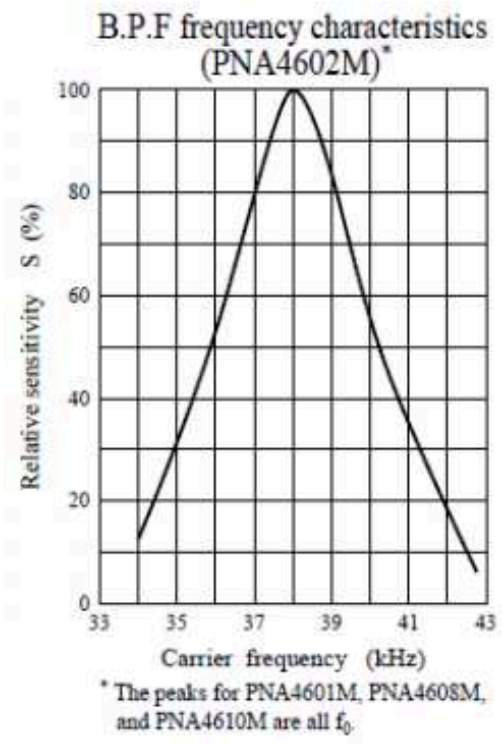

(a)

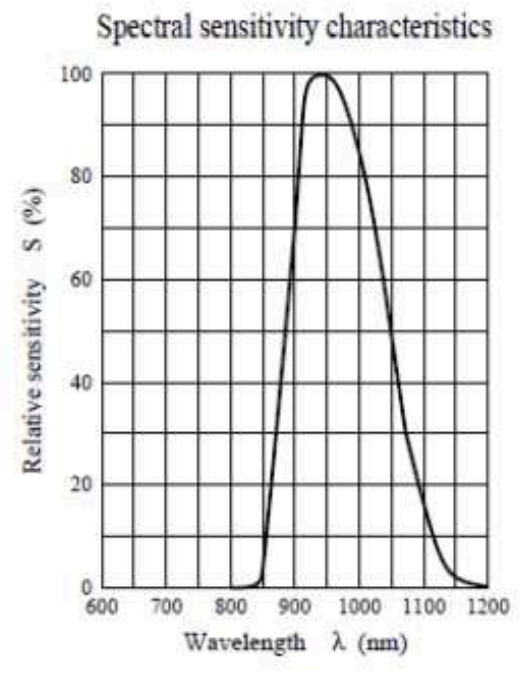

(b)

Fig. 8(a) e 8(b) - Curvas fornecidas pelo Datasheet do Receptor IR, Sensibilidade Relativa pela frequência Portadora (lado esquerdo) e Sensibilidade Relativa pelo comprimento de onda (lado direito).

\section{Procedimentos}

Na Fig. 9 mostramos o esquema da montagem utilizada para a obtenção do código hexadecimal de cada tecla do controle remoto, bem como o arranjo que consiste em um LED RGB (vermelho, verde e azul) e um sensor de luz LDR (Light Dependent Resistor). Atribuiremos funções diferentes para cada tecla do controle remoto, visando alterar a cor e a intensidade de luz no LED RGB e a consequente resposta obtida pelo LDR para cada uma destas condições, já que sua sensibilidade depende da região espectral da radiação incidente. 


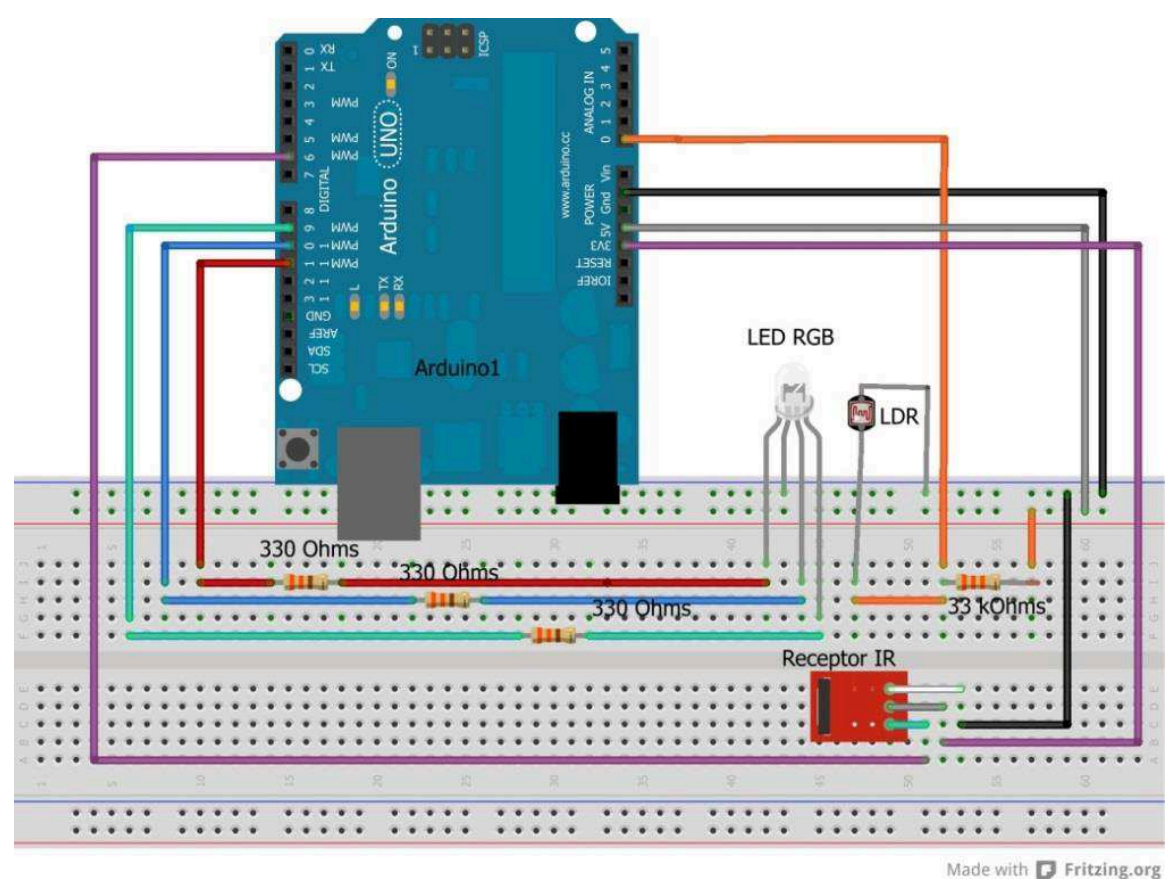

Fig. 9 - Projeto da nossa montagem.

A Fig. 10 mostra a montagem final que foi disposta numa caixa de madeira (Fig. 10a e 10b) visando tanto a proteção e a locomoção do circuito, como a redução da interferência da luz externa no LDR.

Para possibilitar a composição de diferentes cores e a alteração de intensidade de cada componente, se conecta as entradas do LED RGB às portas digitais PWM (Pulse Width Modulation) ${ }^{2}$; 11,10 e 9 do Arduíno. Estas portas simulam uma saída analógica a partir da largura do sinal digital. Sinais que permanecem mais tempo em estado alto permitem uma maior intensidade do LED e menor tempo em estado baixo menor intensidade.

${ }^{2}$ Noções básica sobre saídas PWM. Disponível em:

$<$ http://googolplex.com.br/arduino/entendendo-pwm-no-arduino $>$. Acesso em: 12 mai. 2014. 


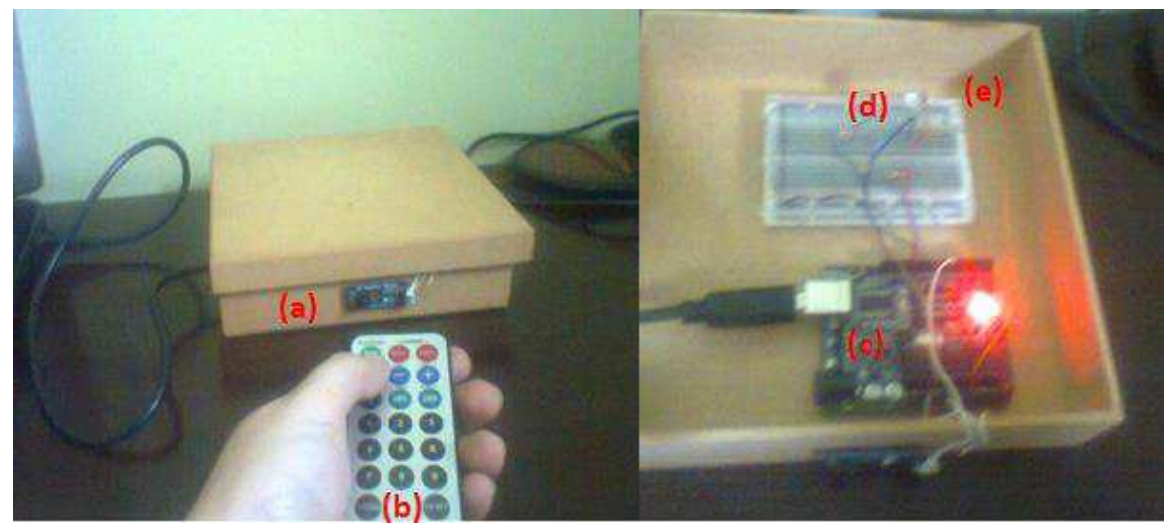

Fig. 10 - Montagem final do nosso projeto, lado externo (lado esquerdo) e lado interno (lado direito). Sendo os componentes: (a) Receptor IR, (b) Controle Remoto IR, (c) Arduíno, (d) LED RGB e (e) LDR.

Inicialmente utilizamos uma programação da biblioteca IRremote ${ }^{3}$, para testarmos o receptor IR e então anotamos quais são os valores hexadecimais e binários de cada tecla, para uso na programação. Após a verificação dos códigos de cada tecla, usamos uma programação de controle remoto IR, baseada na biblioteca disponível NECIRrcv ${ }^{4}$, para acionamento do LED RGB, controle de intensidade e cor e a correspondente medida da tensão na porta analógica em que está conectado o foto-sensor LDR. No anexo dois disponibilizamos a programação utilizada. O quadro (4) mostra a tecla do controle remoto e o comando correspondente.

\footnotetext{
${ }^{3}$ Tutorial para o uso do sensor IR com Arduíno. Disponível em: <https://learn.adafruit.com/ir-sensor/overview>. Acesso em: 12 mai. 2014.

4

Biblioteca para uso do sensor IR no Arduino versão 1.0 em diante (NECIRrcv). Disponível em: <http://labduino.blogspot.com.br/2012/10/controle-remoto-e-arduino-reciclando.html> Acesso em: 12 mai. 2014.
} 
Quadro (4) - Comandos do Arduíno para cada tecla do controle remoto.

\begin{tabular}{ll}
\hline Tecla & Função \\
\hline EQ & Apagar a Luz \\
Tecla 1 & Acender Luz Vermelha \\
Tecla 2 & Acender Luz Verde \\
Tecla 3 & Acender Luz Azul \\
Tecla 4 & Acender Luz Amarela (Vermelho +Verde) \\
Tecla 5 & Acender Luz Lilás (Vermelho + Azul) \\
Tecla 6 & Acender Luz Azul Claro (verde + azul) \\
Tecla 7 & Acender Luz Branca (vermelho+verde+azul) \\
\hline
\end{tabular}

\section{Resultados}

\section{VI.1 Códigos Hexadecimais obtidos pelo Arduíno}

O quadro (5) fornece o código Hexadecimal de cada uma das teclas e no anexo 1, fornecemos a programação utilizada para a obtenção destes códigos.

Quadro (5) - Binário e código hexadecimal correspondente a cada tecla do controle remoto utilizado: CAR mp3.

\begin{tabular}{lll} 
Tecla & Binário & Hexadecimal \\
\cline { 1 - 2 } Play & 1000000101111111000000001111111 & 40BF00FF \\
\cline { 1 - 2 } CH- & 1000000101111110100000010111111 & $40 \mathrm{BF} 807 \mathrm{~F}$ \\
\hline $\mathrm{CH}+$ & 1000000101111110010000011011111 & $40 \mathrm{BF} 40 \mathrm{BF}$ \\
\hline EQ & 1000000101111111010000001011111 & $40 \mathrm{BF} 20 \mathrm{DF}$ \\
\hline Vol - & 100000010111111011000001001111 & $40 \mathrm{BFA05F}$ \\
\hline Vol + & 1000000101111110001000011101111 & $40 \mathrm{BF} 609 \mathrm{~F}$ \\
\hline 0 & 1000000101111111001000001101111 & $40 \mathrm{BF} 10 \mathrm{EF}$ \\
\hline Prev & 1000000101111110101000010101111 & $40 \mathrm{BF} 906 \mathrm{~F}$ \\
\hline Next & 1000000101111110011000011001111 & $40 \mathrm{BF} 50 \mathrm{AF}$ \\
\hline 1 & 1000000101111111011000001001111 & $40 \mathrm{BF} 10 \mathrm{EF}$ \\
\hline 2 & 1000000101111110111000010001111 & $40 \mathrm{BFB} 04 \mathrm{~F}$ \\
\hline 3 & 1000000101111110000100011110111 & $40 \mathrm{BF} 708 \mathrm{~F}$ \\
\hline 4 & 1000000101111111000100001110111 & $40 \mathrm{BF} 08 \mathrm{~F} 7$
\end{tabular}




\begin{tabular}{lll}
\hline 5 & 1000000101111110100100010110111 & $40 \mathrm{BF} 8877$ \\
\hline 6 & 1000000101111110010100011010111 & $40 \mathrm{BF} 48 \mathrm{~B} 7$ \\
\hline 7 & 1000000101111111010100001010111 & $40 \mathrm{BF} 28 \mathrm{D} 7$ \\
\hline 8 & 1000000101111110110100010010111 & $40 \mathrm{BFA} 857$ \\
\hline 9 & 1000000101111110001100011100111 & $40 \mathrm{BF} 6897$ \\
\hline PICK SONG & 1000000101111110101100010100111 & 40BF18E7 \\
\hline
\end{tabular}

Convém observar que os códigos obtidos para cada uma destas teclas podem ser visualizados a partir do software Audacity e correlacionados com os valores indicados pelo Arduíno. Note que os código no item II.3 com o Audacity para as telas EQ, tecla 4 e tecla 6 estão em total compatibilidade com os valores indicados no quadro 5.

\section{VI.2 Recepção de intensidade em um LDR para cada cor fixada no led RGB}

A radiação emitida pelo LED RGB será recebida por um sensor LDR através da leitura em uma porta analógica do Arduíno.

O objetivo desta medida é verificar se a resposta do LDR apresenta sensibilidade diferente para cada cor emitida pelo LED RGB. O diagrama para o circuito utilizado da Fig. 11 é do tipo resistor Pull-up mostra que o sinal é retirado nos terminais do sensor LDR.

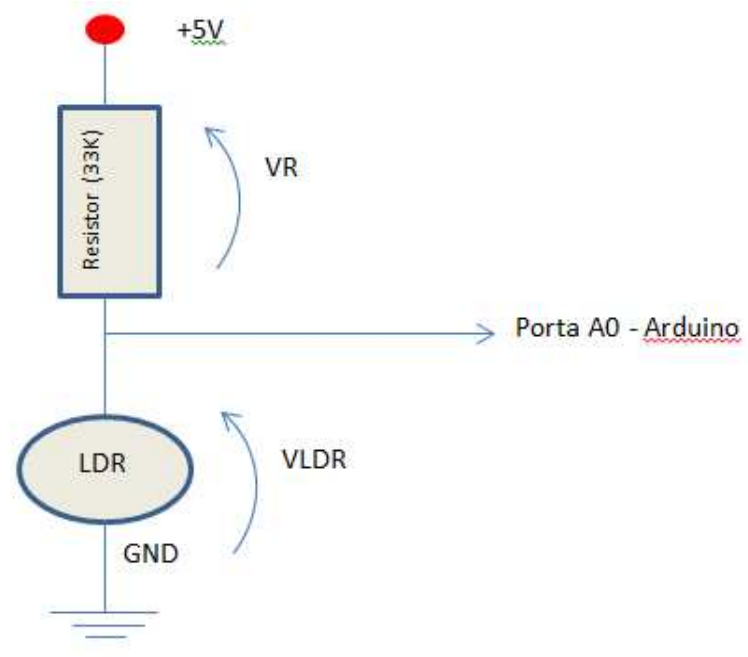

Fig. 11 -Diagrama de blocos do circuito para leitura no fotossensor LDR. 
O quadro (6) fornece os resultados obtidos para o valor de tensão em cada componente do circuito, corrente elétrica e resistência no LDR, para cada uma das teclas do controle remoto, que resulta em diferentes cores.

Quadro (6) - Medição da Corrente Produzida no circuito com o LDR, a partir da utilização do LED RGB.

\begin{tabular}{cccccc}
\hline COR & LDR & $\begin{array}{c}\text { V LDR } \\
(\mathbf{V})\end{array}$ & $\begin{array}{c}\text { VR } \\
(\mathbf{V})\end{array}$ & $\mathbf{I}(\mathbf{m A})$ & $\begin{array}{c}\text { R LDR } \\
(\mathbf{k} \Omega)\end{array}$ \\
\hline VERMELHO & 74 & 0,36 & 4,64 & 0,141 & 2,55 \\
VERDE & 208 & 1,02 & 3,98 & 0,121 & 8,43 \\
AZUL & 290 & 1,42 & 3,58 & 0,109 & 13,03 \\
$\begin{array}{c}\text { AMARELO (Verde + } \\
\text { Vermelho) }\end{array}$ & 65 & 0,32 & 4,68 & 0,142 & 2,25 \\
$\begin{array}{c}\text { LILÁS (Vermelho + } \\
\text { Azul) }\end{array}$ & 72 & 0,35 & 4,65 & 0,141 & 2,48 \\
AZUL CLARO & 173 & 0,84 & 4,16 & 0,126 & 6,67 \\
$\quad$ BRANCO & 64 & 0,31 & 4,69 & 0,142 & 2,18 \\
DESLIGADO & 916 & 4,47 & 0,53 & 0,016 & 279,38 \\
\hline
\end{tabular}

É importante notar que quanto maior a corrente registrada no circuito em que está conectado o LDR, menor é a resistência no LDR, indicando que mais elétrons foram transferidos para a banda de condução, tornando o LDR um melhor condutor.

Observa-se que para este LDR temos uma melhor condução quando a incidência de luz está na região do vermelho, o que confere com os dados da maioria dos fabricantes deste tipo de fotossensor ${ }^{5}$.

\section{Análises e considerações finais}

Neste trabalho, foi demonstrado como podemos utilizar o Arduíno e o controle remoto infravermelho para o ensino de conceitos em Física Moderna, possibilitando uma melhor compreensão do seu funcionamento.

\footnotetext{
${ }^{5}$ Curva de resposta típica de um LDR. Disponível em:

$<$ https://learn.adafruit.com/photocells/measuring-light>. Acesso em: 12 mai. 2014.
} 
Como se observa no quadro (6), os valores obtidos para as correntes e as resistências do LDR (quando o led está desligado), mantiveram-se constantes e com um valor mínimo, indicando maior resistência para o LDR. Os maiores valores de corrente foram para as cores branca e amarela, vermelha e lilás, sendo: 0,141 $\mathrm{mA}$ e $0,142 \mathrm{~mA}$, respectivamente, ou seja para todas as cores em que a componente vermelha está presente.

O fotossensor utilizado, LDR, é um semicondutor em que, à quebra de ligações covalentes ocorrem devido à ação de fótons, sendo tal processo comumente encontrado em dispositivos que transformam a energia luminosa em elétrica.

No entanto, estes semicondutores, como qualquer dispositivo desta natureza, funcionam numa banda de energia para a radiação incidente e cuja ressonância depende da parcela de impurezas adicionadas em sua estrutura.

Em geral, os LDR comerciais apresentam em suas curvas de sensibilidade espectral maiores respostas para a região do vermelho/laranja, como mostra a Fig. 12. Note que os resultados observados no quadro 6 comprovam esta sensibilidade espectral para o LDR, visto se obter maiores correntes elétricas exatamente para as cores onde esta componente espectral está presente.

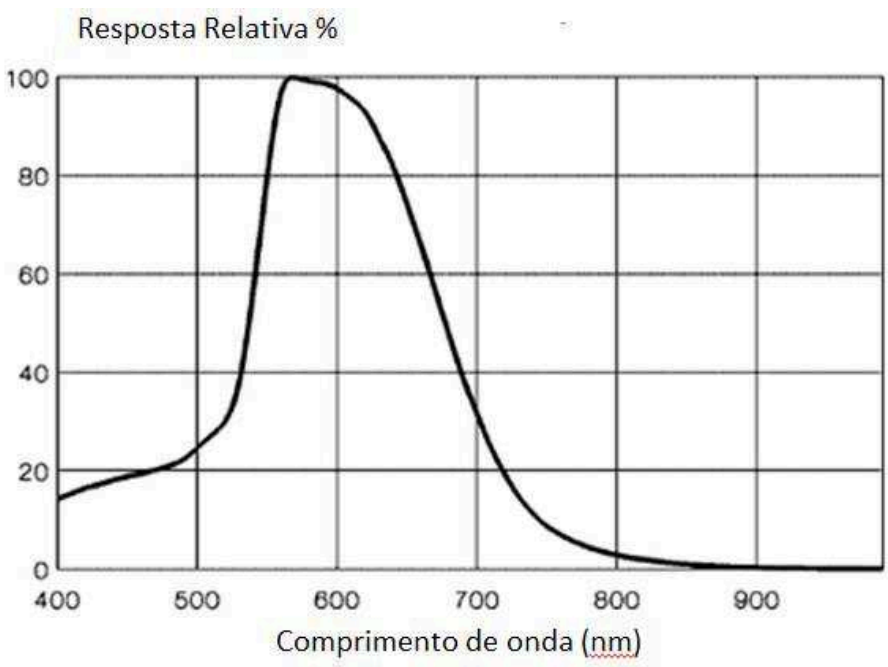

Fig. 12 - Resposta espectral relativa para $u m L D R^{6}$.

${ }^{6}$ Curva de resposta típica de um LDR. Disponível em:

$<$ https://learn.adafruit.com/photocells/measuring-light>. Acesso em: 12 mai. 2014. 
Tal experimento demonstra ser um interessante recurso para ilustrar a Física Moderna através do uso da tecnologia, pois além de propiciar uma boa interatividade dos alunos com o dispositivo, os materiais utilizados são de baixo custo e de fácil acesso para todos os professores, possibilitando uma fácil difusão nas escolas.

Podemos observar os sinais provenientes de um controle remoto de diferentes modos, desde uma simples visualização em câmera digital, até a observação do sinal modulado em softwares de análise sonora como o Audacity e finalmente com o Arduíno.

Com a placa Arduíno amplia-se muito mais as possibilidades, já que podemos enviar comandos e executar medidas em experimentos como os propostos neste artigo.

A inserção da placa Arduíno em experimentos didáticos amplia consideravelmente o leque de aplicações e possibilidades, que por um lado permite despertar maior interesse dos estudantes para áreas como Física e Engenharia e de outro possibilita uma maior compreensão das tecnologias disponíveis no cotidiano do século XXI.

\section{Referências bibliográficas}

ALMEIDA JUNIOR, J. N.; CAVALCANTE, M. A.; RODRIGUES, T. T. T. Oscilador amortecido em interface com Arduíno. In: SIMPÓSIO NACIONAL DE ENSINO DE FÍSICA, XX, 2013, São Paulo. Anais... Disponível em: $<$ http://www.sbf1.sbfisica.org.br/eventos/snef/xx/sys/resumos/T0389-1.pdf>. Acesso em: 12 mai. 2014.

ALMEIDA JUNIOR, J. N.; CAVALCANTE, M. A. Construção de um Espectrofotômetro utilizando a placa Arduíno. In: PAEE 2012 - PROJECT APPROACHES IN ENGINEERING EDUCATION, 2012, São Paulo. Anais... Disponível em: $<$ http://prezi.com/wiuyznbo3ihl/construcao-de-um-espectrofotometro-utilizando-aplaca-Arduíno/>. Acesso em: 12 mai. 2014.

Biblioteca NECIRrcv. Disponível em:

$<$ http://labduino.blogspot.com.br/search/label/controle\%20remoto $>$. Acesso em: 12 mai. 2014. 
CACHAPUZ, A.; GIL-PEREZ, D.; CARVALHO, A. M. P; PRAIA, J. VILCHES, A. A necessária renovação do Ensino das Ciências. São Paulo: Editora Cortez, 2005.

CAVAlCANTE, M. A; RODRIGUES, T. T. T.; BUENO, D. A. Controle Remoto: principio de funcionamento (parte 1 de 2). Caderno Brasileiro de Ensino de Física, v. 3. n. 3, p. 554, 2013. Disponível em:

$<$ https://periodicos.ufsc.br/index.php/fisica/article/view/2175-7941.2013v30n3p 554>. Acesso em: 12 mai. 2014.

CAVALCANTE, M. A.; TAVOLARO, C. R. C.; MOLISANI, E. Física com Arduíno para iniciantes. Revista Brasileira de Ensino de Física, v. 33, n. 4, p. 4503. São Paulo, 2011. Disponível em:

$<$ http://www.scielo.br/scielo.php?script=sci_arttext\&pid=S1806-11172011000400 018\&lng=pt\&nrm=iso\&tlng=en>. Acesso em: 12 mai. 2014.

CAVALCANTE, M. A.; RODRIGUES, C. E. M.; PONTES, L. A. Novas tecnologias no estudo de ondas sonoras. Caderno Brasileiro de Ensino de Física, v. 30, n. 3, p. 579, 2013. Disponível em:

$<$ https://periodicos.ufsc.br/index.php/fisica/article/view/27176>. Acesso em: 12 mai. 2014.

CAVALCANTE, M. A.; TAVOLARO, C. R. C.; MOLISANI, E. Potencialidades do Arduíno na Aprendizagem por Projetos. In: SIMPÓSIO NACIONAL DE ENSINO DE FÍSICA, XX, 2013, São Paulo. Anais... Disponível em: $<$ http://www.sbf1.sbfisica.org.br/eventos/snef/xx/sys/resumos/T0270-1.pdf $>$. Acesso em: 12 mai. 2014.

CAVALCANTE, M. A.; BARBOSA, L. M.; TAVOLARO, C. R. C.; MOLISANI, E.; RANZINI, E. Potencialidades do Arduíno na Aprendizagem por Projetos para alunos do curso de Ciência da Computação da PUC/SP. In: SEMINÁRIO WEBCURRÍCULO DA PUC/SP, III, 2012, São Paulo. Anais... Disponível em: $<$ https://drive.google.com/\#folders/0B6YRUIKRU7Q-ZWc2dEVrX2t6ODg>. Acesso em: 12 mai. 2014.

CAVALCANTE, M. A.; TAVOLARO, C. R. C.; MOLISANI, E.; LAURATO, R. A. High Tech Dante: Ciência e Tecnologia na Construção do Conhecimento. In: SEMINÁRIO WEBCURRÍCULO DA PUC/SP, III, 2012, São Paulo. Anais... Disponível em: 
<https://drive.google.com/\#folders/0B6YRU1KRU7QZWc2dEVrX2t6ODg>. Acesso em: 12 mai. 2014.

DATASHEET DO SENSOR IR. Disponível em:

$<$ http://html.alldatasheet.com/html-pdf/78724/KODENSHI/KSM-603LM/651/2/ KSM-603LM.html>. Acesso em: 12 mai. 2014.

DROSE, N. B. Aprendizagem de conceitos físicos relacionados com circuitos elétricos em regime de corrente alternada com uso da placa Arduíno. 2013. Dissertação (Mestrado em Ensino de Física) - UFRGS, Porto Alegre. Disponível em: <http://www.lume.ufrgs.br/handle/10183/79523>. Acesso em: 12 mai. 2014.

FIGURA DA RESPOSTA ESPECTRAL RELATIVA PRO LDR. Disponível em: $<$ http://learn.adafruit.com/photocells/measuring-light $>$. Acesso em: 12 mai. 2014.

\section{LIBÂNEO, J. C. Adeus Professor, Adeus Professora? Novas exigências educa-} cionais e profissão docente. Questões da Nossa época. 13. ed. Editora Cortez, São Paulo, 2013. v. 2.

MOLISANI, E.; TEIXEIRA, R. M. R.; CAVALCANTE, M. A. Arduíno e Ferramentas da Web 2.0 no Ensino de Física: Um exemplo de aplicação em Ótica. In: SIMPÓSIO NACIONAL DE ENSINO DE FÍSICA, XX, 2013, São Paulo. Anais... Disponível em: $<$ http://www.sbf1.sbfisica.org.br/eventos/snef/xx/sys/resumos/T0551-1.pdf>. Acesso em: 12 mai. 2014.

SOUZA, A. R. de; PAIXÃO, A. C.; UZÊDA, D. D.; DIAS, M. A.; DUARTE, S.; AMORIM, H. S. de. A placa Arduíno: uma opção de baixo custo para experiências de física assistidas pelo PC. Revista Brasileira de Ensino de Física, v. 33, n. 1, p. 1702, São Paulo, 2011. Disponível em:

<http://www.sbfisica.org.br/rbef/pdf/331702.pdf >. Acesso em: 12 mai. 2014.

TUTORIAL DO RECEPTOR IR. Disponível em: <http://learn.adafruit.com/irsensor/overview>. Acesso em: 12 mai. 2014.

LINK PARA BAIXAR A BIBLIOTECA IR Disponível em: <http://www.arcfn.com/2010/11/irremote-library-now-runs-on-teensy.html>. Acesso em: 12 mai. 2014. 


\section{Anexo 1}

Código utilizado para ler os comandos do controle remoto em hexadecimal e binário

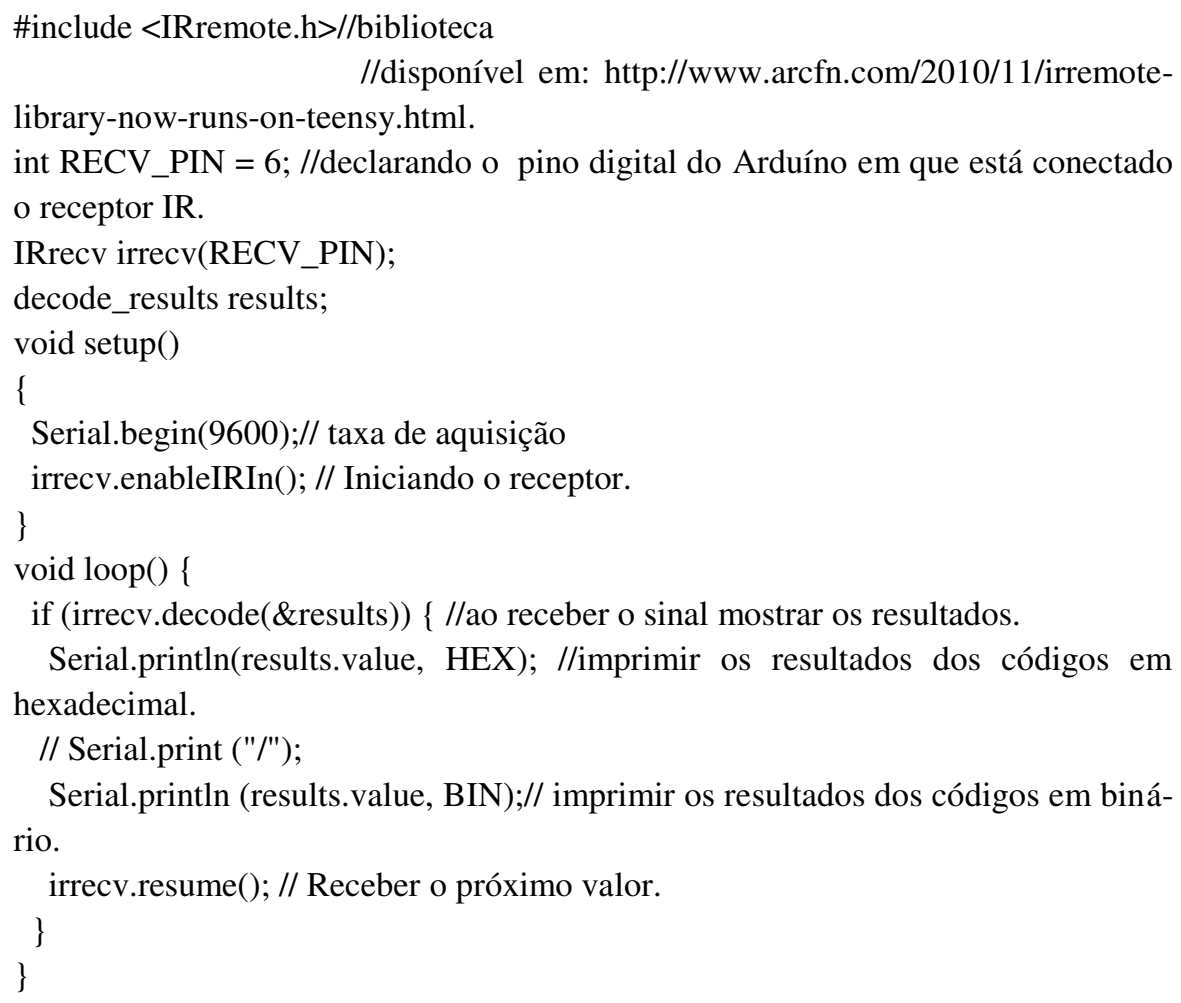

Serial.println(results.value, HEX); //imprimir os resultados dos códigos em hexadecimal.

// Serial.print ("/");

Serial.println (results.value, BIN);// imprimir os resultados dos códigos em binário.

irrecv.resume(); // Receber o próximo valor.

\}

\section{Anexo 2}

\section{Código Utilizado para controlar cores de um LED RGB}

\#include <NECIRrcv.h> // bliblioteca para controle remoto disponível em

//https://www.dropbox.com/sh/53bp7fo211hxbba/iYnG2cqfhN/Biblioteca\%20NE CIRrcv\%20para\%20controle\%20remoto \#include <Arduíno.h> // biblioteca para versoes superiores a 1.0 do Arduíno 
\#define InfraVermelho 6 // entrada digital em que o receptor IR é conectado ao Arduíno.

\#define botao0 4144561410 // código em decimal para cada tecla do controle remoto.

\#define botao 14077714690

\#define botao2 4061003010

\#define botao3 4044291330

\#define botao4 4010867970

\#define botao5 3994156290

\#define botao6 3977444610

\#define botao7 3944021250

\#define botao8 3927309570

\#define botao9 3910597890

\#define EQ 4211408130

\#define VOL1 4177984770

\#define VOL2 4194696450

\#define PLAY 4278254850

int brightness $=0 ; \quad / /$ variável que controla o brilho do LED.

int fadeAmount $=10 ; \quad / /$ intervalo de variação que será usado para variar a intensidade do LED.

$/ /($ quanto menor este numero mais ajuste fino).

unsigned long int capturaCodigo $=0 ; / /$ definição da variável de captura do código do controle

//que corresponde a um numero decimal

inteiro e maior

//do que 32bits.

float LDR; //declara variável ao fotosensor.

float VLDR; // Tensão LDR.

float RLDR; // declara a tensão do resistor do circuito associado ao LDR.

float I;// declara a corrente no circuito do LDR.

NECIRrcv ir(InfraVermelho);

int vermelho=11; // pino em que o terminal vermelho do LED RGB está conectado ao Arduíno.

int verde $=10$; // pino em que o terminal verde do LED RGB está conectado ao Arduíno.

int azul=9; // pino em que o terminal azul do LED RGB está conectado ao Arduíno. 


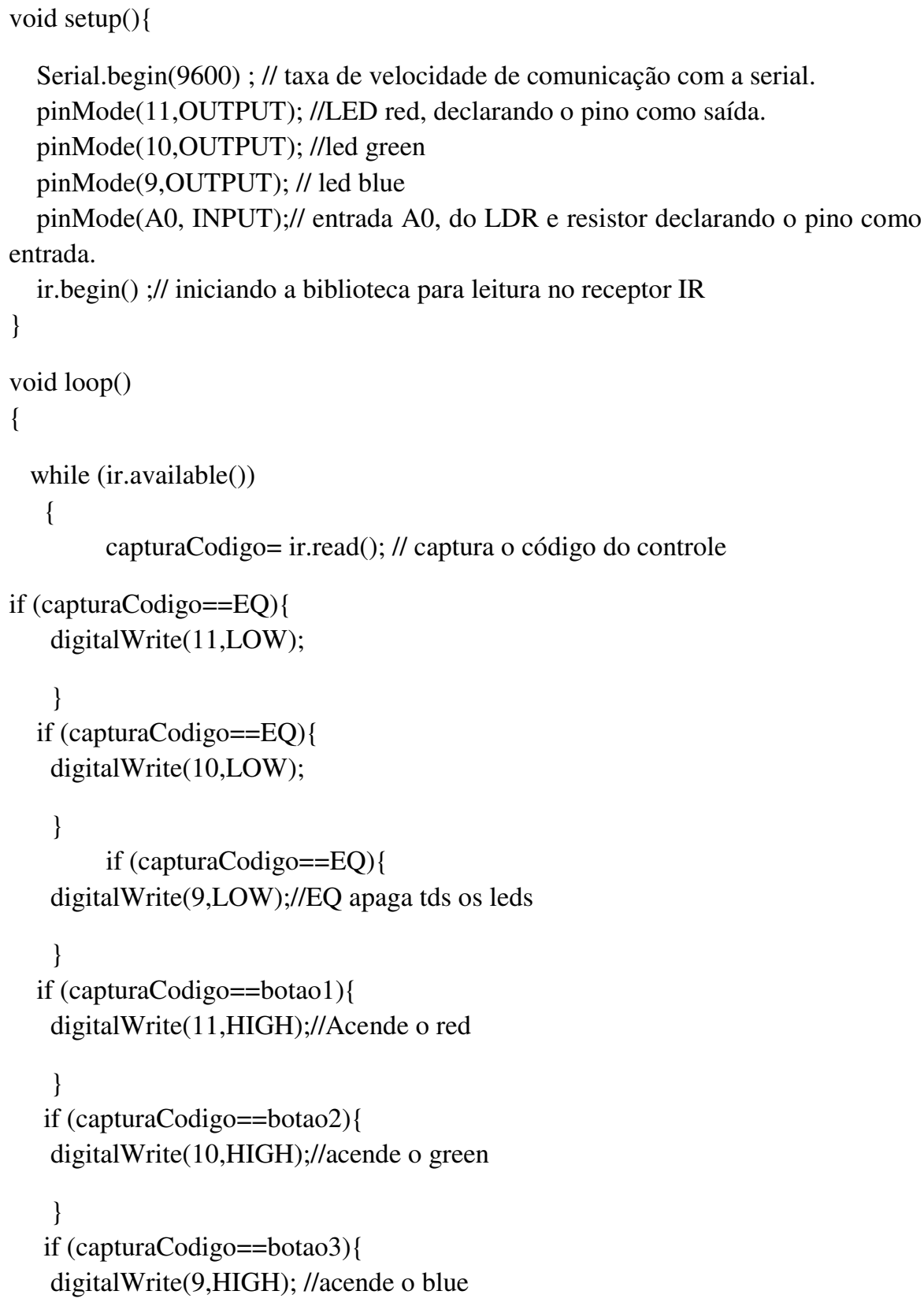




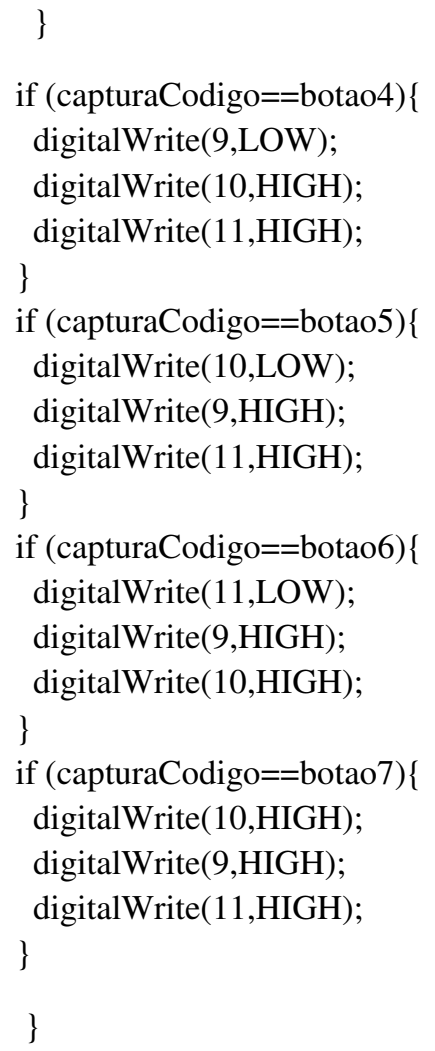

LDR = analogRead(A0); // leitura no foto-sensor LDR.

VLDR=LDR*5.0000000/1024; // transformando esta informação para tensão em Volts

$\mathrm{VR}=5.00000-\mathrm{VLDR}$; // tensão no resistor no circuito do LDR.

I= RLDR/33; // corrente no circuito do LDR em mA.

if (capturaCodigo==botao1) \{ //comando ao teclar o botão 1 iniciar a impressão dos //valores de leitura de: LDR, VLDR, RLDR, I, no monitor serial.

Serial.print(LDR);

Serial.print("/");

Serial.print(VLDR);

Serial.print("/"); 
Serial.print(RLDR);

Serial.print("/ ");

Serial.println(I, 3);

\}

if (capturaCodigo==botao2) \{ //inicio do comando de leitura ao clicar no botão 2 .

Serial.print(LDR);

Serial.print("/");

Serial.print(VLDR);

Serial.print("/");

Serial.print(RLDR);

Serial.print("/ ");

Serial.println(I, 3);

\}

if (capturaCodigo==botao3) \{ //inicio do comando de leitura ao clicar no botão 3 .

Serial.print(LDR);

Serial.print("/");

Serial.print(VLDR);

Serial.print("/");

Serial.print(RLDR);

Serial.print("/ ");

Serial.println(I, 3);

\}

if (capturaCodigo==botao4) \{ //inicio do comando de leitura ao clicar no botão 4 .

Serial.print(LDR);

Serial.print("/");

Serial.print(VLDR);

Serial.print("/");

Serial.print(RLDR);

Serial.print("/ ");

Serial.println(I, 3);

\}

if (capturaCodigo==botao5)\{ //inicio do comando de leitura ao clicar no botão 5 .

Serial.print(LDR);

Serial.print("/");

Serial.print(VLDR);

Serial.print("/");

Serial.print(RLDR);

Serial.print("/ "); 
Serial.println(I, 3);

\}

if (capturaCodigo==botao6) $\{$ //inicio do comando de leitura ao clicar no botão 6 . Serial.print(LDR);

Serial.print("/");

Serial.print(VLDR);

Serial.print("/");

Serial.print(RLDR);

Serial.print("/ ");

Serial.println(I, 3);

\}

if (capturaCodigo==botao7)\{ //inicio do comando de leitura ao clicar no botão 7 . Serial.print(LDR);

Serial.print("/");

Serial.print(VLDR);

Serial.print("/");

Serial.print(RLDR);

Serial.print("/ ");

Serial.println(I, 3);

\}

if (capturaCodigo==EQ) \{ //inicio do comando de leitura ao clicar no botão EQ.

Serial.print(LDR);

Serial.print("/");

Serial.print(VLDR);

Serial.print("/");

Serial.print(RLDR);

Serial.print("/ ");

Serial.println(I, 3);

\}

\}

\} 